\title{
Determinants of leader cells in collective cell migration $\dagger$
}

\author{
Antoine A. Khalil ${ }^{a}$ and Peter Friedl ${ }^{* b}$ \\ Received 16th June 2010, Accepted 13th August 2010 \\ DOI: $10.1039 / \mathrm{coib00052c}$
}

Collective migration is a basic mechanism of cell translocation during morphogenesis, wound repair and cancer invasion. Collective movement requires cells to retain cell-cell contacts, exhibit group polarization with defined front-rear asymmetry, and consequently move as one multicellular unit. Depending on the cell type, morphology of the group and the tissue context, distinct mechanisms control the leading edge dynamics and guidance. Leading edge migration may either result from adhesion to ECM and contractile pulling, or from forward pushing. The leading edge consists of either one or few dedicated tip cells or a multicellular leading row that generate adhesion and traction towards the tissue substrate. Alternatively, a multicellular bud consisting of many cells protrudes collectively by proliferation and growth thereby mechanically expanding and pushing towards the tissue stroma. Each type of collective guidance engages distinct spatiotemporal molecular control and feedback towards rearward cells and the adjacent tissue microenvironment; these include intrinsic polarity mechanisms regulated by the interplay between cell-cell and cell-ECM interactions; or the heterotypic integration of stromal cells that adopt leader cell functions. We here classify molecular and mechanical mechanisms of leading function in collective cell migration during morphogenesis and wound repair and discuss how these are recapitulated during collective invasion of cancer cells.

\section{Introduction}

Cell migration is a fundamental process leading to the position change of cells on or within the tissue environment. Cells can either move individually, termed single-cell migration, or as multicellular units with cell-cell junctions retained, termed collective cell migration. ${ }^{1,2}$ Whereas single-cell migration depends upon mechanotransduction and signaling cascades within the same cell, in collective cell migration these functions are shared between different cells to reach coordinated, "supracellular" translocation. The morphologies and organization of moving cell groups vary depending on the cell and tissue context, ranging from moving multicellular sheets to clusters, strands, or tubes (Fig. 1). Because of its organized shape, collective migration is central to the formation of

\footnotetext{
${ }^{a}$ Department of Dermatology, University of Würzburg, Würzburg, Germany.E-mail: antoine.khalil@stud-mail.uni-wuerzburg.de

${ }^{b}$ Department of Cell Biology, Nijmegen Centre for Molecular Life Sciences, Radboud University Nijmegen Medical Centre.

E-mail:P.Friedl@ncmls.ru.nl

$\dagger$ Published as part of a themed issue on Mechanisms of Directed Cell Migration: Guest Editors David Beebe and Anna Huttenlocher.
}

complex tissue structures, such as glands and epithelia during morphogenesis and during wound repair (Fig. 1(A)) and, in less well controlled form, cancer invasion ${ }^{3}$ (Fig. 1(B)).

Similar to single-cell migration, all collective migration modes are dependent on polarized actomyosin-driven interaction with surrounding tissue structures at the leading edge, leading to the displacement of cells relative to the substrate. In single-cell migration, the underlying mechanotransduction occurs within the same cell body by subcellular formation of functional zones, i.e. leading edge protrusion and engagement with the substrate and rear-end retraction leading to translocation of the cell body. In collective migration, these functions are coordinated within individual and between neighboring cells via their cell-cell junctions. ${ }^{2}$ Thus, cells retain their cell-cell adhesion and communication to collectively polarize and migrate directionally. Thereby, the group of cells behaves as a multi-cellular unit, a "super-cell".

Two morphologically and functionally distinct regions determine the direction and efficiency of collective cell migration, the leading and trailing edge. The leading edge of moving cell groups consists of one or several cells, termed pathfinder, leading or tip cells which explore the tissue environment, find

\section{Insight Box}

Collective cell migration is a principal migration mode in morphogenesis, regeneration and cancer which depends upon complex cell-cell and cell-tissue interactions. Both, temporary activation and long-lasting differentiation define leader cells of moving cell groups to undergo partial epithelial-to-mesenchymal transition. We here classify how leader cells guiding migrating cell groups become selected by intrinsic and extrinsic signals to polarize, interact with tissue matrix and generate mechanotransduction. 
the path, generate traction and, where needed, proteolytically remodel ECM for path generation. ${ }^{4-7}$ As hallmark, leading cells are intrinsically bipolar, as their front engages with the tissue substrate while their rear region remains engaged with the neighbor cells. ${ }^{8,9}$ Intrinsic bipolarity is maintained by mechanotransduction through integrins that engage with extracellular matrix at free pole of the cell and cadherin-based cell-cell junctions at the other side. In living tissues, this intrinsic bipolarity receives additional input from extracellular signals, such as chemokine and growth factor signaling (Table 1). Using examples from cell movement in morphogenesis, epidermal wound repair and cancer invasion we here first classify morphologies and force generation mechanisms in

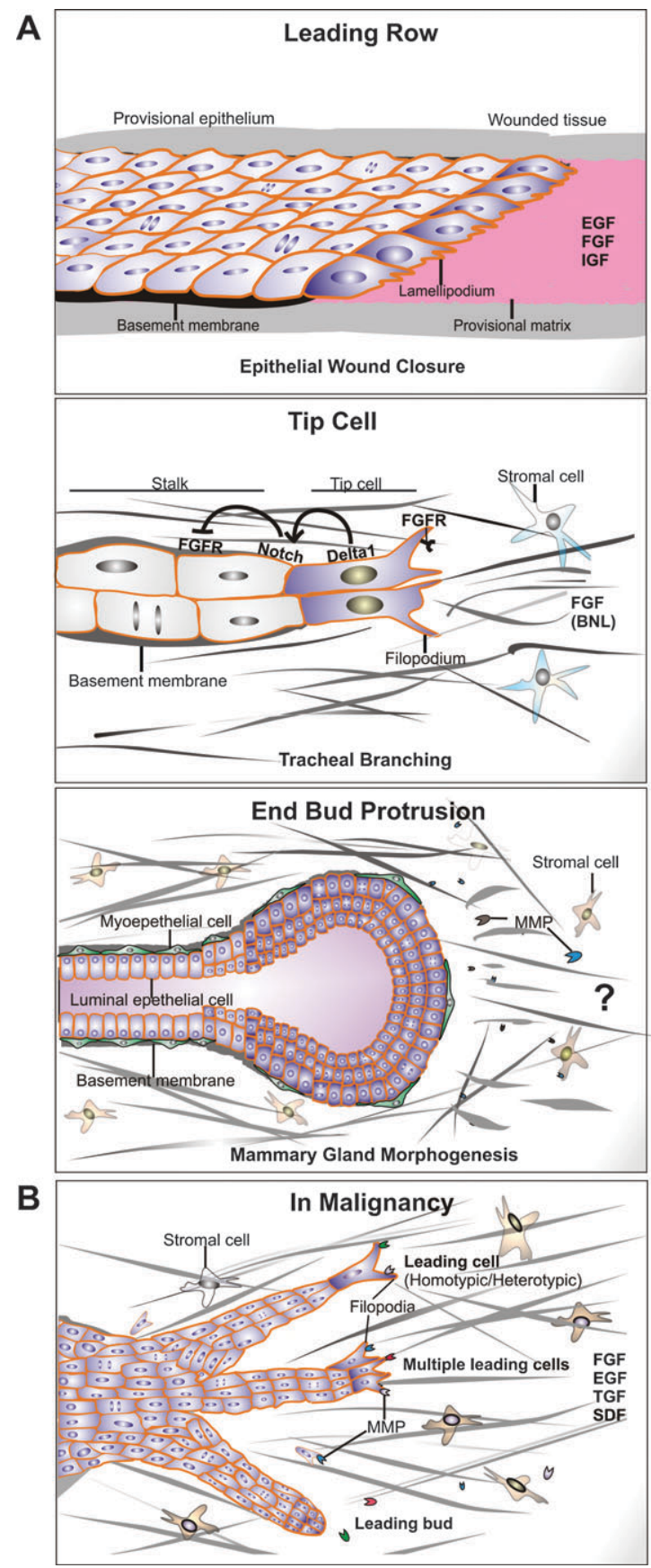

collective migration and then discuss the signaling control to select and maintain different leader cell types and functions.

\section{Diversity of leading edge morphology and function}

The morphology and biomechanics of the leading edge region can be classified into different types based on the number of cells that lead the group, how they interact with the ECM substrate, and their positioning relative to neighboring cells. Further, distinct leading edge mechanics comprise either pulling on or pushing towards ECM substrate leading to physically distinct types of collective movement.

\section{Collective traction}

In most cases of collective leader cells, microenvironmental sensing for guidance cues and mechanotransduction are mediated by extending filopodia and/or lamellipodia which protrude and give rise to focalized adhesions between tissue structures and the intracellular cytoskeleton. ${ }^{6,10,11}$ After anterior attachment, pulling forces towards ECM are generated by actomyosin-driven contraction of the cell body so that the ECM is displaced and realigned towards the leading edge of the group. ${ }^{8,12}$ Leader cells that generate traction force recapitulate many characteristics of leading edge mechanics in single cells, including substrate-induced and directed integrin-mediated

Fig. 1 Diversity of leading edge morphology and function in collective cell migration. (A) Morphogenesis and tissue regeneration. Top panel: in epithelial wound healing, epidermal cells migrate as multicellular sheets maintaining cell-cell contacts (orange). The leading row (shaded color) is multicellular, extends cytoplasmic protrusions and guides following cells over the two dimensional substratum in response to extracellular cues, including growth factors. The leading row contacts a provisional matrix composed of interstitial ECM components with different physicochemical properties than the newly secreted basement membrane underlying the trailing cells. Mid panel: during Drosophila tracheal branching, one or two cells (shared color) are selected to guide the sprouting of new branch in response to FGF. FGF upregulates Deltal expression in the tip cell which in turn binds to Notch that is localized on the membrane of neighboring stalk cells. Notch activation leads to the inhibition of FGFR signaling in stalk cells, preventing the trailing cells to acquire the tip cell phenotype. Bottom panel: in mammary gland morphogenesis, the terminal end bud (TEB) leads the invasion of mammary ducts into the mammary fat pad. The TEB (shaded color) is a multi-layered epithelium which exhibit high rates of proliferation and cellular rearrangement. While invading the stroma, TEB transforms into a bilayered duct consisting of myoepithelial cells and luminal epithelial cells, whereby the differentiated luminal epithelial cells are covered with a myoepithelial cell layer and a newly deposited basement membrane. On the other hand, TEBs have a partial myoepithelial coverage and are surrounded by a thin basement membrane. Whereas the end bud protrudes mostly driven by growth, the ducts provide stable rearward anchorage and lack migration dynamics. Stromal cells including fibroblasts and macrophage are involved in releasing several soluble factors and proteases that are essential for the invasion of TEB and duct elongation yet the signals which induce and maintain directionality of the ductal elongation are not completely understood. (B) Diversity of tip-cell morphology in cancer invasion. Provisional model describing three general forms of malignant collective invasion through the $3 \mathrm{D}$ interstitial tissue, as deduced from morphogenesis. 
Table 1 Major morphogenesis- and tumor-associated soluble and ECM ligands and their effect on leading edge functions

\begin{tabular}{|c|c|c|c|c|}
\hline Ligand & Receptor & $\begin{array}{l}\text { Intracellular mediators } \\
\text { (GTPases and Kinases) }\end{array}$ & Cellular response & References \\
\hline \multirow[t]{3}{*}{ VEGF } & VEGFR2 & $\mathrm{Cdc} 42 / \mathrm{SAPK} 2$ & Filopodia and Polarization & 71 \\
\hline & & Racl/PAK and RhoA & Lamellipodia and Stress Fibers & 72,73 \\
\hline & & RhoA, FAK and Rac1/Vav2 & Migration & $74-76$ \\
\hline \multirow{2}{*}{ FGF } & FGFR & $\mathrm{Cdc} 42$ & Filopodia and Polarization & 77 \\
\hline & & Cdc42/PI3K and ERK & Migration & 78,79 \\
\hline \multirow[t]{3}{*}{ EGF } & EGFR & $\mathrm{Cdc} 42$ & Filopodia and Polarization & 80 \\
\hline & & $\begin{array}{l}\text { RhoA, RhoC, Vav1/ERK, FAK } \\
\text { and Rac1/Src-PI3K }\end{array}$ & Migration & $81-83$ \\
\hline & & $\mathrm{Rac1}, \mathrm{Cdc} 42$ & $\begin{array}{l}\text { Lamellipodia and other Membrane } \\
\text { Protrusions }\end{array}$ & 84 \\
\hline \multirow[t]{2}{*}{ TGF- $\beta$} & TGFR & $\begin{array}{l}\text { RhoA/PI3K-Akt, RhoB/ERK, } \\
\text { and Cdc42/PAK }\end{array}$ & Migration & $85-87$ \\
\hline & & Cdc42, RhoA & $\begin{array}{l}\text { Lamellipodia and other Membrane } \\
\text { Protrusions }\end{array}$ & 88 \\
\hline \multirow[t]{2}{*}{ PDGF } & PDGFR & $\begin{array}{l}\operatorname{Racl} / \mathrm{PAK}, \mathrm{Akt} / \mathrm{Rac} / \mathrm{Cdc} 42, \\
\operatorname{Rap} 1 / \operatorname{Racl}\end{array}$ & Migration & $89-91$ \\
\hline & & $\mathrm{Racl} / \mathrm{PI} 3 \mathrm{~K}$ & Membrane Ruffles & 92 \\
\hline SDF-1 & CXCR4 & $\begin{array}{l}\text { Cdc42, PI3K/Akt, Rap, } \\
\text { Rac1-Cdc42/PAK1 }\end{array}$ & Migration & $93-96$ \\
\hline \multirow[t]{2}{*}{ IGF-1 } & IGFR & PI3K, Racl & Membrane Ruffles, Lamellipodium & 97,98 \\
\hline & & Rac1, ROCK & Migration & 47,99 \\
\hline \multicolumn{5}{|l|}{ ECM Component } \\
\hline $\mathrm{N} / \mathrm{A}$ & Integrin $\alpha \mathrm{v} \beta 3$ and $\alpha \mathrm{v} \beta 5$ & $\begin{array}{l}\text { Cdc } 42 / \text { WASP, Rac1/PAK, } \\
\text { RhoA/ROCK, ERK }\end{array}$ & Migration & 100 \\
\hline Laminin-10/11 & Integrin $\alpha 3 \beta 1$ & $\mathrm{Rac} / \mathrm{p} 130 \mathrm{Cas}$ & Lamellipodia and Migration & 99 \\
\hline $\mathrm{N} / \mathrm{A}$ & Integrin $\alpha 6 \beta 4$ & Rac1/TIAM1, PI3K & Migration & 101,102 \\
\hline Collagen & $\mathrm{N} / \mathrm{A}$ & MAPK/MLCK & Migration & 103 \\
\hline $\mathrm{N} / \mathrm{A}$ & $\alpha 3 \beta 1$ & Rho, FAK/Src/RAcl & $\begin{array}{l}\text { Stress Fibers, Polarization and } \\
\text { Migration }\end{array}$ & 99 \\
\hline $\mathrm{N} / \mathrm{A}$ & $\alpha 5 \beta 1$ & RhoA & $\begin{array}{l}\text { Acto-myosin Contraction and } \\
\text { Random Migration }\end{array}$ & 104 \\
\hline
\end{tabular}

adhesion to ECM followed by actomyosin-dependent contraction of the cell body and retraction of the cell rear. ${ }^{13,14}$ Depending on the number of leading cells and the substrate encountered, traction-generating leading edges form distinct mono-, oligo- or multicellular organisation geometries. A multicellular broad and flat rim of cells leads epithelial sheet migration over $2 \mathrm{D}$ substratum during the wound closure of skin or regenerating corneal epithelium (Fig. 1(A))., ${ }^{8,16}$ In sprouting vessels and branching morphogenesis of the Drosophila tracheal system, one or two leading cells initiate and guide a strand-like multicellular stalk (Fig. 1(A)), and similar single-cell tips have been described in collective cancer invasion (Fig. 1(B)). ${ }^{4,5,7}$ Likewise, few defined leader cells form an oligocellular leading group followed by stalk-like collective strands, as during lateral line migration in the zebrafish embryo or broad invasive fronts of invasive cancer ${ }^{6,12,17,18}$ (Fig. 1(B)). Cells at leading positions further execute pericellular proteolysis and thereby form or enlarge the physical path of migration. ${ }^{7,19,20}$ Because of their focalized adhesion and traction force characteristics, leading cells develop an extended, spindle-shaped morphology with loss of apical basal polarity ${ }^{21}$ or, on 2D substrate, a spread-out adhesive morphology with abundant stress fibers which, together with the engagement of surface proteases, are characteristics of mesenchymally-moving cells. ${ }^{2,22}$ In most cases, the leader cells remain in guiding position for hours and longer ${ }^{23,24}$ and are stabilized by cellular contact with the trailing cells through adherens, desmosomal and tight junctions. ${ }^{25-27}$ In collective sheet migration, besides the front row of cells, cells within the group contribute to traction force generation by forming basal membrane protrusions ("cryptic lamellipodia") that engage with the underlying substrate and generate active motility. ${ }^{28,29}$ Because not all cells always pull into the same direction, the driving force for collective motion might be the net result integrating multiple force vectors ("tug-of-war") so that supracellular tensile stress across the cell-cell-junctions moves the group towards the direction of the leading edge. ${ }^{29}$

\section{Collective pushing}

When the leading region comprises several cells but forms a blunt smooth rim that lacks actin-rich protrusions and adhesion sites towards the tissue environment, the known hallmarks of adhesion and traction force generation mechanisms are lacking; instead, leading bud movement appears to occur through volume expansion and pushing elongation (Fig. 1(A)). This mode of protrusion mechanics is obvious in mammary and embryonic salivary gland formation, yet mechanistically poorly understood. ${ }^{30,31}$ Leading buds lack a leader cell at stably defined position but rather consist of multiple cells that are mobile and exchange position relative to their neighbors so they dynamically adapt and rearrange bud morphology. ${ }^{30,31}$ Pushing forces and the net movement may in part result from expansive growth driven by proliferation of cells within and adjacent to the bud. ${ }^{32}$ The nature of cell-matrix interactions at the tip of leading buds is currently unknown; likewise the mechanism of matrix remodeling for path generation remain to be identified yet likely includes the participation of stromal cells. ${ }^{33}$ 


\section{Molecular triggers for leading edge selection}

Several mechanisms lead to the formation and maintenance of leading functions in collective cell migration. These include intrinsic polarity, differentiation and heterocellular assistance.

\section{Intrinsic polarity}

The most fundamental mechanism generating leading cell function in multi-cellular migration results from the constitutive front-rear asymmetry governed by the leading edge engaged with ECM structures and lateral and rear parts engaged in cell-cell contacts. Thereby a constitutive yet transient and reversible polarity is generated, here referred to as intrinsic polarity. Cell-cell contact has long been known to negatively modulate actin-driven protrusions and migration (contact inhibition of migration). ${ }^{34,35}$ Among the cell-cell contact molecules implicated in contact inhibition of migration are cadherin-based calcium-dependent junctions that control the actin cytoskeleton through several actin-regulatory proteins such as catenins, Rho GTPases, Arp $2 / 3$ complex and Ena/VASP. ${ }^{36,37}$ On the one hand side, short-term cadherin engagement activates $\mathrm{Rac}$ and $\mathrm{Cdc} 42$ which promote protrusive membrane dynamics, including lamellipodia and filopodia. ${ }^{38,39}$ Once stable, however, established cell-cell adhesions inhibit membrane protrusions in part by activating RhoA which antagonizes Racl activity and thereby actin-mediated protrusions. ${ }^{40-44}$ The best-studied model of generating intrinsic bipolarity in leader cells is the migration of cephalic neural crest cells which originate as cohesive strand and later dissociate into to single cell streaming. ${ }^{45}$ The intrinsic bipolarity of cells leading the group involves cytoplasmic protrusions and Rac1 activity at the leading edge to generate traction force, whereas $N$-cadherin mediated cell-cell contact at the trailing edge silences Racl and maintains a non-migratory interphase to the neighboring cells (contact inhibition of migration). ${ }^{45}$ In sprouting endothelial cells, VE-cadherin-based cell-cell contact inhibits Rac1 activation through Rho-kinase-dependent myosin light-chain 2 (MLC2) phosphorylation and thereby silences FGFR2-mediated protrusion and sprouting at cell-cell junctions. ${ }^{40}$ Leading cell polarity further requires non-canonical Wnt signalling which, via disheveled, activates RhoA and ROCK. ${ }^{41}$ Rho/ROCK signaling, in turn, may inhibit Rac-mediated cytoskeletal protrusions and thereby confine protrusion formation to regions outside of cadherin-based junctions. Additional pathways, directly or indirectly, contribute to contact inhibition of migration along cell-cell junctions, including Notch/Delta signaling, engagement of ephrins and/or atypical cadherins, ${ }^{35}$ and cell-cell contact through tight junctions and gap junctions. ${ }^{46}$ Opposed to the cell-cell contact zone, the leading edge receives constitutive signals from the surrounding tissue through receptors that receive input from ECM and ECM-associated molecules, including integrin adhesion receptors and growth factor and chemokine receptors. ${ }^{9,47}$ In response to ECM, integrins provide transient adhesion signaling and cytoskeletal mechanotransduction through intracellular kinases and adapter proteins, including the focal adhesion kinase (FAK), Src kinases, p130CAS and paxilin (Table 1). ${ }^{48}$ These signals result in leading edge protrusion, adhesive interaction with the substrate and further enhance adjacent receptor tyrosine kinase (RTK) signaling. ${ }^{49}$

Intrinsic leading cell polarity may further result from differential availability of ECM ligands in front versus rear parts of migrating groups when ECM is deposited by the moving cells themselves. In moving keratinocyte sheets, leading keratinocytes moving towards the wound bed interact with dermal collagen together with provisional matrix, such as fibrin and fibronectin and therefore engage $\alpha 2 \beta 1, \alpha 5 \beta 1$ and $\alpha v \beta 3$ integrins for adhesion and force generation. ${ }^{8,50}$ Because moving keratinocytes remodel the underlying ECM and synthesize basement membrane components, cells further rearward interact with newly deposited collagen type IV and laminin which engage different and less promigratory sets of integrins $(\alpha 6 \beta 1, \alpha 6 \beta 4) .{ }^{50}$ Likewise, in sprouting vessels, tip cells encounter primordial (during morphogenesis) or provisional (during wound healing) ECM whereas stalk cells move on a basement membrane that is newly deposited alongside the invading vessel strand. ${ }^{51,52}$ Thus, differential substrate availability contributes to intrinsic polarity in collective migration. Similar mechanisms of intrinsic polarity are present during collective cancer cell invasion. Here, leading cancer cells engage with native interstitial collagen which they subsequently degrade using MT1-MMP/MMP14; consequently the front part engages with native ECM whereas rearward parts of the tip cell, like following cells in the strand, contact partially degraded and restructured collagen. ${ }^{7,13}$ Thus, pericellular proteolysis generates distinct ECM conditions along the length axis of the tip cell. Intrinsic bipolarity is present in all types of tip cells based upon bipolar signaling from cell-ECM and cell-cell interactions. Because of its constitutive nature, even in the absence of chemoattractants, intrinsic polarity may induce and maintain leading edge functions constitutively and reversibly.

\section{Induced differentiation}

Partial or complete differentiation into a leading cell can be induced by extracellular cues, particularly growth factors and other soluble mediators. Depending on the context, tip cell fate is induced by RTK signaling, including FGFR, VEGFR and EGFR and downstream signaling via PI3K, Akt, MAPK activation and Rho GTPases (Table 1) and, ultimately, altered gene expression. The differentiation into single or multiple tip cells initiates the formation of branched ducts in tracheal morphogenesis. In Drosophila tracheal morphogenesis, multicellular tracheal ducts form and branch in response to FGF released by primordial ectodermal and mesodermal cells adjacent to the tracheal placode. ${ }^{53}$ As first step, FGF binding to its receptor FGFR, leads to the activation of several intracellular mediators including downstream of FGFR (Dof) and the tyrosine phosphatase Cockscrew (Csw), to initiate the membrane-proximal FGFR signaling complex. ${ }^{54,55}$ Downstream FGFR signaling engages the ERK/MAPK pathway which regulates actin rearrangement and subsequent filopodia and lamellipodia extensions. ${ }^{10,54,56}$ The FGF-induced tip cell phenotype is maintained by a Ras/MAPK mediated positive feedback mechanism that upregulates FGFR expression in tip cells. $^{57}$ With initial tip cell selection, FGFR signaling is 
inhibited in the neighboring cells through cell-cell contacts, consistent with a transient differentiation step. In response to high FGF levels, tip cells upregulate Delta1 membrane protein which, in turn, activates its receptor Notch in neighbor cells and thereby inhibits FGF/MAPK signaling in following cells. ${ }^{58}$ Spatial restriction of FGF signaling to tip cells further involves FGFR-mediated MMP2 expression; ${ }^{59}$ after its release MMP2 inhibits FGF-induced ERK phosphorylation in stalk but not tip cells through an incompletely understood mechanism. Consequently, in MMP2-/- embryos, ubiquitous FGF/MAPK signaling prompts ectopic tip cell selection and secondary tracheal defects. ${ }^{59}$ Thus an initially not predetermined cell becomes selected by local growth factor signaling, develops into a tip cell, and, in turn, inhibits cytoskeletal activity in neighbor cells. ${ }^{60}$

Soluble factor-induced selection of tip cells preceding collective cell migration is recapitulated in other morphogenic processes, including vascular sprouting, formation of the lateral line, and migrating border cells. In sprouting angiogenesis single tip cells that lead the budding of neo-vessels from preexisting vessels is induced by VEGFR2 signaling through VEGFA released by stromal cells, including astrocytes, fibroblasts, or epithelial cells, depending on the context. ${ }^{11,61,62}$ Migration-promoting VEGFR2 signaling activates Cdc42 and downstream p21-activated kinase (PAK) for the induction of filopodia extension. ${ }^{11}$ Endothelial tip cells upregulate the Notch-ligand Dll4 which signals to Notch1 in neighbor cells and determines stalk cell differentiation. ${ }^{63-65}$ Endothelial tip cells further upregulate VEGFR2 and platelet derived growth factor B (PDGFB) ${ }^{66}$ which both stabilize their responsiveness to environmental guidance. Whereas in sprouting of tracheal ducts and blood vessels a single or two cells are defined to lead the group, the lateral line in Zebra fish is guided by a group of 10 to 20 leader cells along a path defined by SDF-1 released by the stroma. ${ }^{67,68}$ The leading group depends upon asymmetric expression of CXCR4 present in leading and CXCR7 in trailing cells. ${ }^{6,69}$ Whereas CXCR4 leads to promigratory signaling in leading cells, CXCR7 in other parts of the lateral line is thought to act as a sink for SDF-1 and, hence, a dominant-negative receptor. ${ }^{69,70}$ This bipolar expression CXCR4 and CXCR7 is induced and maintained by differential FGF and $\mathrm{Wnt} / \beta$-catenin signaling. ${ }^{23} \mathrm{Wnt} / \beta$-catenin signaling is confined to tip cells where it induces the paracrine secretion of FGF which in turn inhibits $\mathrm{Wnt} / \beta$-catenin signaling in trailing cells through the Dickkopf-related protein 1 (DKK1). ${ }^{23}$ In parallel, tip cells silence the FGFR pathway by expressing the FGF-inhibitor sef. ${ }^{23}$ Thus, tip cell selection and at least transient differentiation result from local growth factor signaling followed by secondary inhibition of migration activity in neighboring cells.

\section{Heterocellular-assistance}

If a migrating group consists of two or several cell types with distinct origin or differentiation state, the leading and following cells can be from distinct cell lineages. In collective invasion of epithelial cancer cells in organotypic cultures, stromal fibroblasts can adopt heterotypic tip cell function and lead the invasion of the cancer cells. ${ }^{105}$ Leading fibroblasts induce matrix remodeling and generate tracks of least resistance by an integrin- and MMP-dependent mechanism. ${ }^{105}$ The type of heterocellular cell junctions between leading and following cells is not clear yet but consistent with concepts on direct heterotypic cell-cell junctions between cancer and stromal cells. ${ }^{106-108}$ Thus, both induced differentiation and heterocellular assistance eventually lead to similar outcome, i.e. a structurally and functionally distinct set of leading cells to generate mechanotransduction as well as a proteolytic trail of least resistance.

\section{End bud protrusion}

Terminal end buds (TEB) of the mammary gland are highly proliferative multi-cell layered structures which lead the branching of mammary ducts. The mechanisms of TEB movement include high proliferative activity, dynamic cellular position change within the end bud, and likely the coupling to a relatively rigid stalk which prevents rearward sliding of the protruding bud. ${ }^{33}$ The mechanisms that initiate and coordinate these distinct functions are not fully understood, but involve cell-to-cell contacts, cell-ECM interactions and growth factor signaling. Quiescent mammary epithelial cells retain direct basolateral contact with myoepithelial cells which form a continuous layer around the luminal cells and express the smooth muscle actin and myosin which provide cortical cytoskeletal stability and contractility. ${ }^{109}$ Conversely, mammary duct protrusion and branching mainly takes place in regions that are devoid from stable contact to myoepithelial cells. Myoepithelial cells directly contribute to mammary epithelial cell differentiation through heterocellular interactions via desmosomes and gap junctions and indirectly through the deposition of several basement membrane components including laminin-1 $1^{110-113}$ and thus likely act as inhibitors of cell protrusion formation and tip cell functions. Through a mechanical mechanism, myoepithelial cells may also prevent epithelial outgrowth by forming stable cell-cell junctions and by their own contractility which laterally confines the emerging duct. ${ }^{32}$ Consequently, end-bud proliferation and protrusion dynamics may result from the rarefication or absence of heterotypic cell-cell contact to myoepithelial cells and contact-dependent differentiation and anchoring signals.

In addition, differential ECM composition surrounding the end bud and stalk may account for functional control of end bud protrusion. Mature mammary epithelial ducts are covered by a thick basement membrane composed of collagen type IV, laminin-1/5 and fibronectin. ${ }^{114,115}$ The TEB is surrounded by a thin, provisional basement membrane containing laminin-1, collagen IV and, in addition, high levels of hyaluronic acid. $^{116,117}$ Besides the basement membrane, differential processing of ECM components between TEB and ductal regions is provided by differentially expressed MMPs. MT1-MMP/MMP-14 and MMP-2 are highly expressed by stromal cells nearby the TEBs, whereas MMP-3 is present nearby quiescent ducts. ${ }^{118-120}$ Particularly MMP-2 and MT1-MMP/MMP-14 are important modifiers of the ECM structure which supports cell migration and proliferation and reduces adhesive cell anchoring. ${ }^{114,118}$ End bud protrusion and ductal elongation are further induced and maintained by 
signaling through growth factors, including IGF-1, EGF, HGF, BMP and Wnt. ${ }^{21,119,121}$ The mechanisms by which such factors differentially engage end bud versus ductal behavior are likely diverse and include the induction and maintenance of cell proliferation and growth as well as differential cytoskeletal dynamics leading to tissue invasion. Thus, although end bud protrusion is likely devoid of defined cell-matrix interactions but dependent on growth, followed by secondary volume expansion and forward pushing into an activated stroma, the principles of a leading cell group in differential contact with accessory cells and ECM components are maintained, as in other types of collective cell invasion.

\section{Conclusions}

The diverse and often synergistic mechanisms which select and maintain leader cell functions in collective migration all serve to generate and maintain a bipolar state near the protruding leading edge without compromising cell-cell contacts and structural stability in following cells and, hence, organized tissue geometry. Thereby contact-dependent and paracrine signaling by cell-cell junctions and locally released factors cooperate in a space-restricted context to generate supracellular coordination of group polarity and tissue organization. Likely, morphogenetic invasion is recapitulated during cancer invasion in a very similar albeit less stringently controlled fashion. Thus, the acquisition of mesenchymal properties with retained cadherin-based cell-cell junctions likely overlap, or are identical with, leading-cell function and differentiation in morphogenesis. Thus concepts derived from morphogenic collective invasion may allow to reconcile collective cell functions with the concept of EMT in cancer progression. In both, morphogenesis and cancer, tip cells likely retain a specialized repertoire of activation and differentiation markers which might be amenable to targeted therapy to either support tissue regeneration or inhibit destructive cancer invasion.

\section{Acknowledgements}

This work was supported by a fellowship from the Graduate School for Life Sciences, University of Würzburg (to A.K.). We acknowledge Cindy Dieteren for support in graphics preparation.

\section{Notes and references}

1 R. B. Vaughan and J. P. Trinkaus, J. Cell Sci., 1966, 1, 407.

2 P. Friedl and K. Wolf, J. Cell Biol., 2010, 188, 11.

3 P. Friedl and D. Gilmour, Nat. Rev. Mol. Cell Biol., 2009, 10, 445.

4 E. Caussinus, J. Colombelli and M. Affolter, Curr. Biol., 2008, 18, 1727.

5 S. F. De, I. Segura, B. K. De, P. J. Hohensinner and P. Carmeliet, Arterioscler., Thromb., Vasc. Biol., 2009, 29, 639.

6 P. Haas and D. Gilmour, Dev. Cell, 2006, 10, 673.

7 K. Wolf, Y. I. Wu, Y. Liu, J. Geiger, E. Tam, C. Overall, M. S. Stack and P. Friedl, Nat. Cell Biol., 2007, 9, 893.

8 R. Grose, C. Hutter, W. Bloch, I. Thorey, F. M. Watt, R. Fassler, C. Brakebusch and S. Werner, Development., 2002, 129, 2303.

9 D. Vestweber, Arterioscler., Thromb., Vasc. Biol., 2007, 28, 223. 10 C. Ribeiro, A. Ebner and M. Affolter, Dev. Cell, 2002, 2, 677.

$11 \mathrm{H}$. Gerhardt, M. Golding, M. Fruttiger, C. Ruhrberg, A. Lundkvist, A. Abramsson, M. Jeltsch, C. Mitchell,
K. Alitalo, D. Shima and C. Betsholtz, J. Cell Biol., 2003, 161, 1163.

12 Y. Hegerfeldt, M. Tusch, E. B. Brocker and P. Friedl, Cancer Res., 2002, 62, 2125.

13 P. Friedl and K. Wolf, Cancer Metastasis Rev., 2009, 28, 129.

14 D. A. Lauffenburger and A. F. Horwitz, Cell, 1996, 84, 359.

15 I. K. Gipson, Acta Ophthalmol. Suppl., 1992.

16 P. S. Zelenka and P. Arpitha, Semin. Cell Dev. Biol., 2008, 19, 113.

17 D. Vignjevic, M. Schoumacher, N. Gavert, K. P. Janssen, G. Jih, M. Lae, D. Louvard, A. Ben-Ze'ev and S. Robine, Cancer Res., 2007, 67, 6844 .

18 A. Wicki and G. Christofori, Br. J. Cancer, 2007, 96, 1.

19 K. Nabeshima, T. Inoue, Y. Shimao, Y. Okada, Y. Itoh, M. Seiki and M. Koono, Cancer Res., 2000, 60, 3364.

20 V. W. van Hinsbergh and P. Koolwijk, Cardiovasc. Res., 2008, 78, 203.

21 M. Affolter, R. Zeller and E. Caussinus, Nat. Rev. Mol. Cell Biol., 2009, 10, 831.

22 P. Friedl and K. Wolf, Biochem. Soc. Symp., 2003.

23 A. Aman and T. Piotrowski, Dev. Cell, 2008, 15, 749.

24 P. Friedl, P. B. Noble, P. A. Walton, D. W. Laird, P. J. Chauvin, R. J. Tabah, M. Black and K. S. Zanker, Cancer Res., 1995, 55, 4557.

25 R. Kollmar, S. K. Nakamura, J. A. Kappler and A. J. Hudspeth, Proc. Natl. Acad. Sci. U. S. A., 2001, 98, 10196.

26 G. Li, K. Satyamoorthy and M. Herlyn, Cancer Res., 2001, 61, 3819.

27 M. Tanaka-Matakatsu, T. Uemura, H. Oda, M. Takeichi and S. Hayashi, Development., 1996, 122, 3697.

28 R. Farooqui and G. Fenteany, J. Cell Sci., 2005, 118, 51.

29 X. Trepat, Physical forces during collective cell migration, Nat. Phys., 2009, 5, 426-430.

30 A. J. Ewald, A. Brenot, M. Duong, B. S. Chan and Z. Werb, Dev. Cell, 2008, 14, 570 .

31 M. Larsen, C. Wei and K. M. Yamada, J. Cell Sci., 2006, 119, 3376.

32 D. J. Andrew and A. J. Ewald, Dev. Biol., 2010, 341, 34.

33 B. S. Wiseman and Z. Werb, Science, 2002, 296, 1046.

34 M. Abercrombie, Nature, 1979, 281, 259.

35 R. Mayor and C. Carmona-Fontaine, Trends Cell Biol., 2010.

36 J. M. Halbleib and W. J. Nelson, Genes Dev., 2006, 20, 3199.

37 A. Hartsock and W. J. Nelson, Biochim. Biophys. Acta, Biomembr., 2008, 1778, 660

38 S. H. Kim, Z. Li and D. B. Sacks, J. Biol. Chem., 2000, 275, 36999.

39 M. Nakagawa, M. Fukata, M. Yamaga, N. Itoh and K. Kaibuchi, J. Cell Sci., 2001, 114, 1829.

40 S. Abraham, M. Yeo, M. Montero-Balaguer, H. Paterson, E. Dejana, C. J. Marshall and G. Mavria, Curr. Biol., 2009, 19, 668.

41 C. Carmona-Fontaine, H. K. Matthews, S. Kuriyama, M. Moreno, G. A. Dunn, M. Parsons, C. D. Stern and R. Mayor, Nature, 2008, 456, 957.

42 C. M. Nelson, D. M. Pirone, J. L. Tan and C. S. Chen, Mol. Biol. Cell, 2004, 15, 2943.

43 V. Sanz-Moreno, G. Gadea, J. Ahn, H. Paterson, P. Marra, S. Pinner, E. Sahai and C. J. Marshall, Cell, 2008, 135, 510.

44 N. Taulet, F. Comunale, C. Favard, S. Charrasse, S. Bodin and C. Gauthier-Rouviere, J. Biol. Chem., 2009, 284, 23137.

45 E. Theveneau, L. Marchant, S. Kuriyama, M. Gull, B. Moepps, M. Parsons and R. Mayor, Dev. Cell, 2010, 19, 39.

46 A. A. Khalil, 2010, unpublished work.

47 D. P. Choma, V. Milano, K. M. Pumiglia and C. M. DiPersio, J. Invest. Dermatol., 2007, 127, 31.

48 M. A. Schwartz and M. H. Ginsberg, Nat. Cell Biol., 2002, 4, E65.

49 F. G. Giancotti and G. Tarone, Annu. Rev. Cell Dev. Biol., 2003, 173.

50 B. P. Nguyen, M. C. Ryan, S. G. Gil and W. G. Carter, Curr. Opin. Cell Biol., 2000, 12, 554.

51 R. A. Clark, M. G. Tonnesen, J. Gailit and D. A. Cheresh, Am. J. Pathol., 1996, 148, 1407.

52 J. M. Rhodes and M. Simons, J. Cell. Mol. Med., 2007, 11, 176.

53 D. Sutherland, C. Samakovlis and M. A. Krasnow, Cell, 1996, 87, 1091. 
54 A. M. Michelson, S. Gisselbrecht, E. Buff and J. B. Skeath, Development., 1998, 125, 4379.

55 V. Petit, U. Nussbaumer, C. Dossenbach and M. Affolter, Mol. Cell. Biol., 2004, 24, 3769.

56 S. Vincent, R. Wilson, C. Coelho, M. Affolter and M. Leptin, Mol. Cell, 1998, 2, 515.

57 T. Ohshiro, Y. Emori and K. Saigo, Mech. Dev., 2002, 114,3 .

58 T. Ikeya and S. Hayashi, Development., 1999, 126, 4455.

59 Q. Wang, M. Uhlirova and D. Bohmann, Dev. Cell, 2010, 18, 157.

60 A. S. Ghabrial and M. A. Krasnow, Nature, 2006, 441, 746.

61 T. K. Ito, G. Ishii, H. Chiba and A. Ochiai, Oncogene, 2007, 26, 7194.

62 D. T. Shima, U. Deutsch and P. A. D'Amore, FEBS Lett., 1995, 370, 203.

63 R. Benedito, C. Roca, I. Sorensen, S. Adams, A. Gossler, M. Fruttiger and R. H. Adams, Cell, 2009, 137, 1124.

64 M. Hellstrom, L. K. Phng and H. Gerhardt, Cell Adhes. Migr., $2007,1,133$

65 S. Suchting, C. Freitas, N. F. le, R. Benedito, C. Breant, A. Duarte and A. Eichmann, Proc. Natl. Acad. Sci. U. S. A., $2007, \mathbf{1 0 4}, 3225$.

66 N. Unoki, T. Murakami, K. Nishijima, K. Ogino, R. N. van and N. Yoshimura, Invest Ophthalmol. Vis. Sci., 2010.

67 N. B. David, D. Sapede, L. Saint-Etienne, C. Thisse, B. Thisse, C. Dambly-Chaudiere, F. M. Rosa and A. Ghysen, Proc. Natl. Acad. Sci. U. S. A., 2002, 99, 16297.

68 W. K. Metcalfe, C. B. Kimmel and E. Schabtach, J. Comp. Neurol., 1985, 233, 377

69 C. Dambly-Chaudiere, N. Cubedo and A. Ghysen, BMC Dev. Biol., 2007, 23.

70 B. Boldajipour, H. Mahabaleshwar, E. Kardash, M. ReichmanFried, H. Blaser, S. Minina, D. Wilson, Q. Xu and E. Raz, Cell, 2008, 132, 463.

71 L. Lamalice, F. Houle, G. Jourdan and J. Huot, Oncogene, 2004, 23, 434.

72 E. Ispanovic, D. Serio and T. L. Haas, Am. J. Physiol.: Cell Physiol., 2008, 295, C600.

73 W. Tan, T. R. Palmby, J. Gavard, P. Amornphimoltham, Y. Zheng and J. S. Gutkind, FASEB J., 2008, 22, 1829.

74 R. Braren, H. Hu, Y. H. Kim, H. E. Beggs, L. F. Reichardt and R. Wang, J. Cell Biol., 2006, 172, 151.

75 T. A. Garrett, J. D. Van Buul and K. Burridge, Exp. Cell Res., 2007, 313, 3285.

76 G. P. van Nieuw Amerongen, P. Koolwijk, A. Versteilen and V. W. van Hinsbergh, Arterioscler., Thromb., Vasc. Biol., 2003, 23, 211

77 C. Wolf, N. Gerlach and R. Schuh, EMBO Rep., 2002, 3, 563.

78 J. G. Lee and E. P. Kay, Invest. Ophthalmol. Visual Sci., 2006, 47, 1376.

79 G. Pintucci, D. Moscatelli, F. Saponara, P. R. Biernacki, F. G. Baumann, C. Bizekis, A. C. Galloway, C. Basilico and P. Mignatti, FASEB J., 2002, 16, 598.

80 M. El-Sibai, P. Nalbant, H. Pang, R. J. Flinn, C. Sarmiento, F. Macaluso, M. Cammer, J. S. Condeelis, K. M. Hahn and J. M. Backer, J. Cell Sci., 2007, 120, 3465.

81 R. S. Dise, M. R. Frey, R. H. Whitehead and D. B. Polk, Am. J. Physiol.: Gastrointest. Liver Physiol., 2007, 294, G276.

82 J. Han, L. Li, J. Hu, L. Yu, Y. Zheng, J. Guo, X. Zheng, P. Yi and Y. Zhou, Endocrinology, 2010, 151, 1732.

83 J. L. Wilsbacher, S. L. Moores and J. S. Brugge, Cell Commun. Signaling, 2006, 4(1), 5.

84 K. Kurokawa, R. E. Itoh, H. Yoshizaki, Y. O. Nakamura and M. Matsuda, Mol. Biol. Cell, 2003, 15, 1003.

85 A. V. Bakin, A. K. Tomlinson, N. A. Bhowmick, H. L. Moses and C. L. Arteaga, J. Biol. Chem., 2000, 275, 36803.

86 M. G. Ricos, N. Harden, K. P. Sem, L. Lim and W. Chia, J. Cell Sci., 1999, 112, 1225.
87 E. Vasilaki, E. Papadimitriou, V. Tajadura, A. J. Ridley, C. Stournaras and D. Kardassis, FASEB J., 2010, 24, 891

88 S. Edlund, M. Landstrom, C. H. Heldin and P. Aspenstrom, J. Cell Sci., 2004, 117, 1835.

89 M. Higuchi, N. Masuyama, Y. Fukui, A. Suzuki and Y. Gotoh, Curr. Biol., 2001, 11, 1958.

90 M. Takahashi, Y. Rikitake, Y. Nagamatsu, T. Hara, W. Ikeda, K. Hirata and Y. Takai, Genes Cells, 2008, 13, 549.

91 J. A. Yu, N. O. Deakin and C. E. Turner, Mol. Biol. Cell, 2009, 20, 4706.

92 R. L. Doughman, A. J. Firestone, M. L. Wojtasiak, M. W. Bunce and R. A. Anderson, J. Biol. Chem., 2003, 278, 23036.

93 M. D. Gallego, M. A. de la Fuente, I. M. Anton, S. Snapper, R. Fuhlbrigge and R. S. Geha, Int. Immunol., 2005, 18, 221.

94 E. Haddad, J. L. Zugaza, F. Louache, N. Debili, C. Crouin, K. Schwarz, A. Fischer, W. Vainchenker and J. Bertoglio, Blood, 2001, 97, 33.

95 S. J. McLeod, A. H. Li, R. L. Lee, A. E. Burgess and M. R. Gold, J. Immunol., 2002, 169, 1365

96 J. Yu, M. Li, Z. Qu, D. Yan, D. Li and Q. Ruan, J. Cardiovasc. Pharmacol., 2010.

97 K. Kotani, K. Yonezawa, K. Hara, H. Ueda, Y. Kitamura, H. Sakaue, A. Ando, A. Chavanieu and B. Calas, F. Grigorescu EMBO J., 1994, 13, 2313.

98 S. Y. Nagasawa, N. Takuwa, N. Sugimoto, H. Mabuchi and Y. Takuwa, Biochem. J., 2005, 385, 737.

99 J. Gu, Y. Sumida, N. Sanzen and K. Sekiguchi, J. Biol. Chem., 2001, 276, 27090.

100 L. Lamalice, B. F. Le and J. Huot, Circ. Res., 2007, 100, 782.

101 Z. Cruz-Monserrate and K. L. O'Connor, Neoplasia., 2008, 10, 408.

102 W. Guo and F. G. Giancotti, Nat. Rev. Mol. Cell Biol., 2004, 5, 816.

103 R. L. Klemke, S. Cai, A. L. Giannini, P. J. Gallagher, L. P. de and D. A. Cheresh, J. Cell Biol., 1997, 137, 481.

104 S. Huveneers and E. H. Danen, J. Cell Sci., 2009, 122, 1059.

105 C. Gaggioli, S. Hooper, C. Hidalgo-Carcedo, R. Grosse, J. F. Marshall, K. Harrington and E. Sahai, Nat. Cell Biol., 2007, 9, 1392.

106 M. A. Pollmann, Q. Shao, D. W. Laird and M. Sandig, Breast Cancer Res., 2005, 7, R522.

107 L. Ronnov-Jessen, O. W. Petersen, V. E. Koteliansky and M. J. Bissell, J. Clin. Invest., 1995, 95, 859 .

108 D. Tarin, J. Theor. Biol., 1972, 34, 61.

109 M. C. Adriance, J. L. Inman, O. W. Petersen and M. J. Bissell, Breast Cancer Res., 2005, 7, 190.

110 M. J. Bissell and D. Bilder, Breast Cancer Res., 2003, 5, 117.

111 T. Gudjonsson, M. C. Adriance, M. D. Sternlicht, O. W. Petersen and M. J. Bissell, J. Mammary Gland Biol. Neoplasia, 2005, 10, 261.

112 C. H. Streuli, N. Bailey and M. J. Bissell, J. Cell Biol., 1991, 115 , 1383.

113 R. S. Talhouk, R. Mroue, M. Mokalled, L. Abi-Mosleh, R. Nehme, A. Ismail, A. Khalil, M. Zaatari and M. E. El- Sabban, Exp. Cell Res., 2008, 314, 3275.

114 J. E. Fata, Z. Werb and M. J. Bissell, Breast Cancer Res., 2004, 6,

115 G. B. Silberstein and C. W. Daniel, Dev. Biol., 1982, 90, 215.

116 T. C. Klinowska, J. V. Soriano, G. M. Edwards, J. M. Oliver, A. J. Valentijn, R. Montesano and C. H. Streuli, Dev. Biol., 1999, 215, 13.

117 A. Lochter and M. J. Bissell, Semin. Cancer Biol., 1995, 6, 165.

118 L. Hinck and G. B. Silberstein, Breast Cancer Res., 2005, 7, 245.

119 H. Kouros-Mehr and Z. Werb, Dev. Dyn., 2006, 235, 3404.

120 B. S. Wiseman, M. D. Sternlicht, L. R. Lund, C. M. Alexander, J. Mott, M. J. Bissell, P. Soloway, S. Itohara and Z. Werb, J. Cell Biol., 2003, 162, 1123

121 S. G. Bonnette and D. L. Hadsell, Endocrinology, 2001, 142, 4937. 